\title{
Observation of Inclusion in Aluminum Deoxidized Iron
}

\author{
Kyoko WASAI, Kusuhiro MUKAI and Akifumi MIYANAGA ${ }^{11}$
}

Department of Materials Science and Engineering, Kyushu Institute of Technology, Sensui, Tobata-ku, Kitakyushu $804-8550$ Japan. 1) Formerly Graduate Student, Kyushu Institute of Technology Now at Kyushu Refractories Company Limited, Uraibe, Bizen 705-8609 Japan.

(Received on August 27, 2001; accepted in final form on February 16, 2002)

\begin{abstract}
Aluminum-deoxidized iron at $1873 \mathrm{~K}$ was solidified at 3 different cooling speed; (1) the ultra-rapid cooling of iron using twin rollers, (2) the quenching of iron into copper mold, and (3) the quenching of the iron-bearing crucible in a water bath; the most rapid cooling rate achieved with (1), which was probably about $10^{5} \mathrm{~K} / \mathrm{s}$, followed (2) and (3). Dendritic, maple-like, polygonal, network-like, coral-like and spherical inclusions were observed in the samples. The dendritic, maple-like and polygonal inclusions varied in size from several tens to a few $\mu \mathrm{m}$ and were classified as primary inclusions since their sizes were independent of cooling speed. However, the network-like and coral-like inclusions (in the sample cooled ultra-rapidly and quenched into copper mold), and spherical inclusions were classified as secondary inclusions since they decreased in size with increased cooling speed. A few large spherical inclusions, which would be primary inclusions, were also present.

The analysis of the electronic diffraction of the inclusions established that the $\alpha, \gamma, \delta$-alumina were present as secondary inclusions. An amorphous silica spherical inclusion was also observed.
\end{abstract}

KEY WORDS: inclusion; primary inclusion; secondary inclusion; alumina; hercynite; wüstite; aluminum deoxidation; TEM; amorphous silica.

\section{Introduction}

The steelmakers now face an important target, that of producing an ultra high clean steel by eliminating all inclusions. In contrast, several research studies have focused recently on utilizing inclusions positively. ${ }^{1-5)}$ This technology is referred to as 'oxide metallurgy' and the inclusions are intended to be the nucleation sites for the iron matrix in desirable form and structure. In order to accomplish these objectives, a good knowledge of the mechanism of inclusion formation would be helpful, especially details concerning the first stage of nucleation, the influential factors in nucleation and the process of the growth of the nuclei. The knowledge offers an effective way of eliminating inclusions or controlling its morphology and distribution. Furthermore, the mechanism of nucleation is closely related to the thermodynamical properties of the steel. Thus, a deep knowledge of the thermodynamical properties will also aid the understanding of the mechanism.

In summary, the following problems associated with oxide inclusions still await settlement and need to be clarified or overcome.

(1) In steel, there are two types of oxide inclusions, i.e., primary and secondary inclusions; the former forms after addition of the deoxidizer, whereas the latter forms during cooling or solidification. There are no methods which provide unequivocal, distinctive classification of the two (primary and secondary) types of inclusions.

(2) The presence of $\gamma, \delta, \theta$ and $\kappa$-alumina inclusions has been reported ${ }^{6-10)}$ in iron solidified immediately after aluminum-deoxidation. The $\gamma, \delta, \theta$ and $\kappa$-alumina are unstable at steelmaking temperatures, whereas the $\alpha$-alumina is a stable crystal phase. The reason why and how these aluminas form at steelmaking temperatures is unclear. Also, it is not known whether the unstable aluminas exist as secondary inclusions because the $\gamma, \delta, \theta$ and $\kappa$-alumina phases have been reported to be primary inclusions.

(3) The presence of amorphous silica inclusion in solidified iron has also been reported. ${ }^{7)}$ It is well known that the amorphous silica is easily formed through the solidification of liquid silica. However, the melting point of silica is $1966 \mathrm{~K}^{11)}$ and liquid silica would not be formed in iron in an ordinary manner at steelmaking temperatures. Why and how the amorphous silica is formed is the question.

(4) It is difficult to observe inclusions in liquid iron directly unless by the confocal laser scanning microscope is used. Thus, we are forced to use the solidified sample to study inclusions even though the morphology, the size and the other information may be different to that when in contact with liquid iron.

In the present study, twin rollers were used to study inclusions in the aluminum-deoxidized liquid iron. The twin rollers press the liquid sample between rollers and solidify the sample so quickly that it results in the several kinds of amorphous material. By using this method, liquid iron is solidified very rapidly, and thereby minimizes various changes and reactions which might be expected to occur during cooling and solidification. Comparison of inclusions in the sample solidified by twin rollers with those in the sample quenched in copper mold or water elucidates the 
distinctive ways in which primary and secondary aluminas are formed. The objectives of this study were (1) to confirm the formation of secondary, unstable aluminas and amorphous silica, and (2) carry a thermodynamic inquiry to understand the formation of unstable inclusions.

\section{Experimentals}

\subsection{Apparatus}

The apparatus used in the present experiment consists of a vertical lanthanum chromite $\left(\mathrm{LaCrO}_{3}\right)$ resistance furnace fitted with twin rollers (Fig. 1). A water-cooling jacket seals the top of the alumina tube $(42 \times 35 \times 480 \mathrm{~mm})$ in the furnace. At the other end of the tube, a vessel containing twin rollers is connected in gas-tight condition using $\mathrm{O}-$ ring. The connected part is cooled with a water-jacket. Another vessel for water quenching can be also connected to the aluminum tube in a similar manner. A shutter is mounted in each vessel just under the connection part which protects both the twin rollers and the vessel from thermal radiation. An alumina crucible $(13 \times 9 \times 500 \mathrm{~mm})$ is placed in an alumina tube in the furnace. The alumina crucible was constructed with high grade alumina ( $99.5 \mathrm{mass} \%$ $\mathrm{Al}_{2} \mathrm{O}_{3}, 0.1$ mass $\% \mathrm{SiO}_{2}$ ). The bottom of a long alumina crucible containing the iron sample was sited in the constanttemperature-zone in the alumina tube of the furnace. The top of the alumina crucible was equipped with gas inlet and outlet and a sample addition device. High purity argon gas $(99.999 \%)$ was introduced directly into the crucible from the gas inlet. The gas outlet was closed when twin rollers was used. The gas flows out through an aperture $(0.5$ or

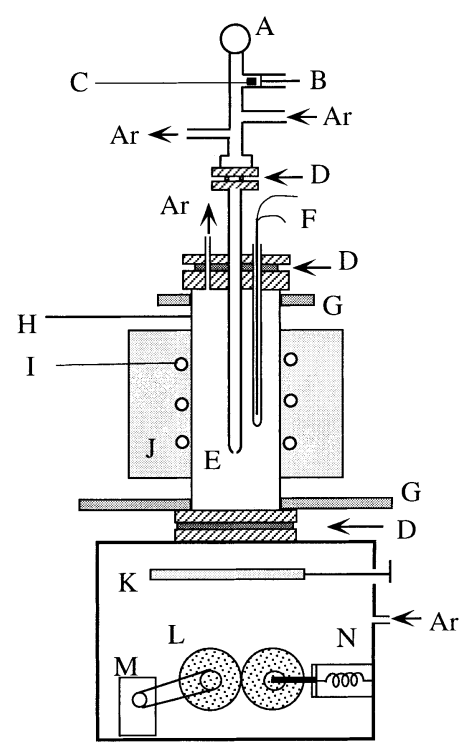
A: Pressure gauge,
$\mathrm{H}$ : Alumina reaction tube
B: Sample dropping device,
I: $\mathrm{LaCrO}_{3}$ Heater,
$\mathrm{C}$ : Iron specimen
$\mathrm{J}$ : Alumina refractory,
D: O-ring,
K: Shutter
E: Alumina crucible,
L:Roller
F: Thermocouple sheath,
M:Motor,
G: Cooling device,

$1 \mathrm{~mm}$ diameter) in the bottom of the crucible. The gas inlet was closed before the melting temperature of iron since the argon pressure tended to force liquid iron drip through the bottom aperture. Then, the argon gas was introduced from the gas inlet attached to the vessel and flowed out through the gas outlet attached to the water-jacket $(50 \mathrm{ml} / \mathrm{min})$. The liquid iron in the crucible can be dripped through the bottom aperture onto the twin rollers placed under the furnace by increasing the argon pressure. The two rollers are contact with each other and can rotate rapidly in opposite directions with the aid of a motor. The liquid iron dropped on it solidifies instantly by sandwiching, pressing and rolling between the rollers which are rotated at high speed (3 100 rpm; ultra-rapid cooling). The liquid iron can also be quenched by lowering the bottom of the crucible quickly into the water, which was introduced just before quenching in the vessel (water quenching). In this case, the alumina crucible with no aperture $(13 \times 9 \times 1000 \mathrm{~mm})$ was used. Argon gas was introduced and flowed out through the gas inlet and outlet at the top of the crucible $(50 \mathrm{~m} / / \mathrm{min})$. Quenching by dripping the liquid iron into a copper mold placed on the shutter or in the vessel can be also performed (copper mold quenching).

The most rapid cooling rate which could be achieved with the ultra-rapid cooling method that was probably about $10^{5} \mathrm{~K} / \mathrm{s}^{12}$ ) followed by the copper mold quenching and water quenching in this order.

\subsection{Experimental Procedure}

\subsubsection{Experiment (1)}

An alumina crucible containing electrolytic iron with 0.0360 mass $\% \mathrm{O}$ was placed in the furnace, and the temperature raised to $1873 \mathrm{~K}$. After arrival at $1873 \mathrm{~K}$, deoxidizer $(\mathrm{Fe}-1.6 \% \mathrm{Al})$ was added to the liquid iron from upper device. After the subsequent temperature drop and recovery within a few minutes, the liquid was maintained at $1873 \mathrm{~K}$ for a certain time $(1,5,15,30,60 \mathrm{~min})$. The added aluminum corresponds to 0.08 mass $\%$ of the total sample weight (about $15 \mathrm{~g}$ ). The sample was then solidified ultrarapidly (Exp. 1-A) or quenched into a copper mold (Exp. 1B).

\subsubsection{Experiment (2)}

Pure aluminum and electrolytic iron containing 0.06250.0675 mass $\% \mathrm{O}$ were added to the crucible which was maintained at $1873 \mathrm{~K}$ in the furnace. The added aluminum quantity corresponds to $0.125 \mathrm{mass} \%$ of the total sample weight (about $15 \mathrm{~g}$ ). After melting, the liquid sample was maintained at $1873 \mathrm{~K}$ for a certain time $(20,40,60 \mathrm{~min})$ and was either solidified ultra-rapidly (Exp. 2-A) or quenched into copper mold (Exp. 2-B). In Exp. 2-C, the liquid sample was maintained at $1873 \mathrm{~K}$ for $20 \mathrm{~min}$ and then quenched in water together with the crucible.

Hereafter, each experiment is referred to as Exp. 1, Exp. 2, Exp. 1-A and so on. Similarly, the solidified sample after the experiment is referred to as Sample 1, Sample 2, Sample 1-A and etc. The terms A, B, C in the experimental and sample numbers represent the solidifying method and cooling speed; the ultra-rapid cooling, the copper mold quenching and the water quenching, respectively.

Fig. 1. Schematic diagrams of experimental apparatus. 


\subsection{Observation by SEM and TEM}

To observe inclusions by SEM and TEM, the iron matrix was dissolved in dilute hydrochloric acid or iodinemethanol solution. Then, the inclusions were filtered using a filter made of polycarbonate or cellulose nitrate, the pore size of which was $0.1 \mu \mathrm{m}$. Even the fine particles smaller than the pore size could be extracted on the filter because such fine particle was apt to adhere to other material and attache firmly. In experiments using hydrochloric acid, alumina and hercynite inclusions, which are insoluble to acid, can be observed on the filter. In experiments using iodinemethanol solution, wüstite inclusions, in addition to alumina and hercynite, were observed. Observation of the filter by EPMA revealed that a long time exposure to electron beam caused damage of the filter and many inclusions were too small to observe, although the moderate size of the inclusion could be observed. Thus, we performed Filter Replica Method for TEM (F.R.M.). This is a new way developed in the present study of observing inclusions on a filter (polycarbonate, $0.1 \mu \mathrm{m}$ pore size) by TEM. Over the filter, the carbon was deposited under vacuum conditions. A few pieces of square part $(0.3 \times 0.3 \mathrm{~mm})$ were cut from the center of the filter. As the polycarbonate is soluble into chloroform, immersion of the cut filters into chloroform causes them dissolution. Then the carbon films, on which many inclusions are adhered, floated up to near the surface of the chloroform solution. Each film can then be scooped onto copper-sheet-mesh, which is usually used to support the TEM sample. After rinsing it with acetone, ethanol and water, the inclusions on the carbon film can be observed by TEM. The Sample 1-A and Sample 1-B were observed by SEM and the Sample 1-A, Sample 2-A, Sample 2-B and Sample 2-C were observed by TEM (F.R.M.).

\subsection{Identification of Inclusion}

The constituent elements of inclusion were analyzed by the EPMA or EDX apparatus belonging to SEM and TEM. The inclusion was identified from the constitution as hercynite, alumina, or wüstite. Electron diffraction analysis of alumina inclusion was also performed and the result was analyzed by taking the crystal forms of $\alpha, \beta, \gamma, \delta, \theta, \kappa^{\prime}$ and $\kappa$-aluminas into consideration. The lattice constants and X-ray diffraction peaks of $\alpha, \beta, \gamma, \delta, \theta$ and $\kappa^{\prime}$-aluminas from the ASTM table were used in the analysis. The lattice constants of $\kappa$-alumina from the report by Adachi et $a l .{ }^{9)}$ were also used. However, identification based only on the diffraction pattern is generally difficult, because many polymorphisms of alumina are present and the patterns of different crystals often coincide with each other within errors of measurement of diffraction spot distance and angle. Therefore, several diffraction patterns from different directions were observed for the inclusion, if any distinct diffraction patterns could be obtained within the rotation limit of sample holder ( \pm 13 degrees for two transverse directions). For the $\gamma$ and $\delta$-alumina, the identification was easier because they often show characteristic diffraction patterns. ${ }^{13)}$ The identification of the inclusion from the diffraction pattern was performed for inclusions where the diameter exceeded about $0.05 \mu \mathrm{m}$ because the diffraction patterns of very fine inclusions were not clear. By contrast, the electric beam could not pass through the large inclusions (a few $\mathrm{mm}$ thickness). Thus, the identification of inclusions with large thickness could not be performed.

\section{Results and Discussion}

Aluminum analysis of the Sample 1-B which was maintained at $1873 \mathrm{~K}$ for $5 \mathrm{~min}$, showed the variation of aluminum content from 0.01 to 0.05 mass $\%$. In order to improve the mixing condition of aluminum, the Exp. 2 was performed but similar aluminum variation (0.03-0.08 mass\% Al) in Sample 2-B (maintained at $1873 \mathrm{~K}$ for $20 \mathrm{~min}$ ) was observed. The formation of alumina primary inclusions at some aluminum-rich position would occur during melting of the sample; the inclusions would float upwards in the liquid iron agglomerating; the solid alumina would be tended to adhere to the crucible wall and subsequently it would grow catching other inclusions and disturb further aluminum diffusion, resulting heterogeneous distribution of alumina and aluminum in the sample for more than 20 min after sample addition in the crucible. However, no marked distinctive differences in the species and the shapes of the inclusions between Sample 1 and Sample 2 were observed. Thus, only the classification of the inclusion's shape and size as a function of cooling speed were analyzed in the present experiment. The chemical species and the crystal structure of alumina were also analyzed.

\subsection{Shape, Size and Species of Inclusion}

Dendritic (Fig. 2), maple-like (Figs. 2(a), 2(b), 2(c)), polygonal (Figs. 2(b), 2(c) and Fig. 4(b)), coral-like (Fig. 4(d)), network-like (Fig. 3 and Figs. 4(a), 4(c)) and spherical inclusions (Figs. 2(a), 2(b), 2(c), Fig. 3 and Fig. 4(a))

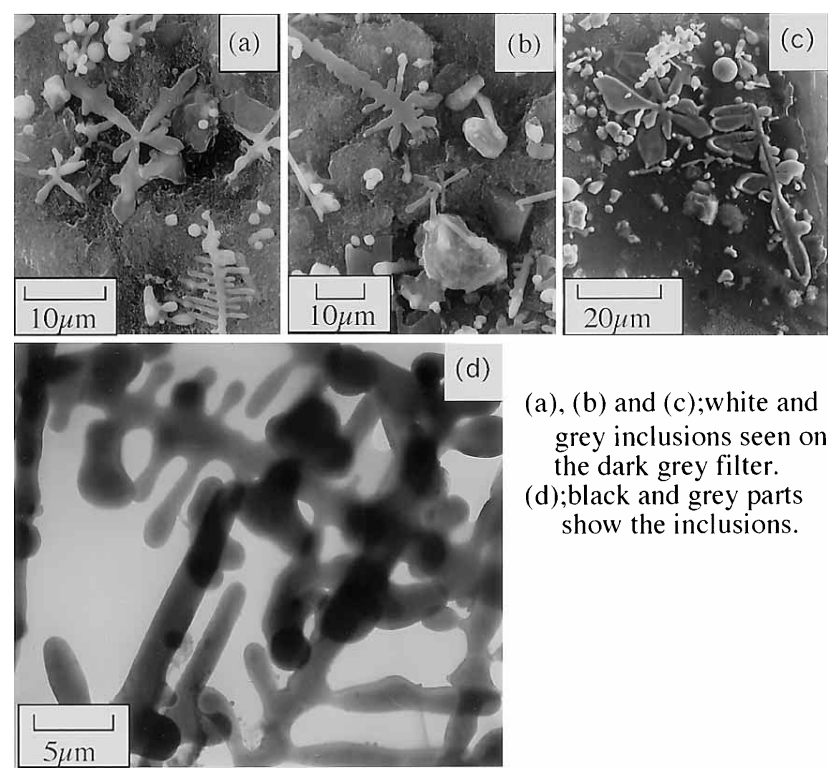

Fig. 2. (a) SEM image of dendritic, maple-like and spherical inclusions on a filter in Sample 1-A maintained at $1873 \mathrm{~K}$ for $1 \mathrm{~min}$. (b) SEM image of dendritic, maple-like, polygonal and spherical inclusions on a filter in Sample 1-A maintained at $1873 \mathrm{~K}$ for $5 \mathrm{~min}$. (c) SEM image of dendritic, maple-like, polygonal and spherical inclusions on a filter in Sample 1-B maintained at $1873 \mathrm{~K}$ for $5 \mathrm{~min}$. (d) Dendritic inclusions in Sample 2-C maintained at $1873 \mathrm{~K}$ for $20 \mathrm{~min}$ (F.R.M.). (a), (b) and (c); white and grey inclusions seen on the dark grey filter. (d); black and grey parts show inclusions. 


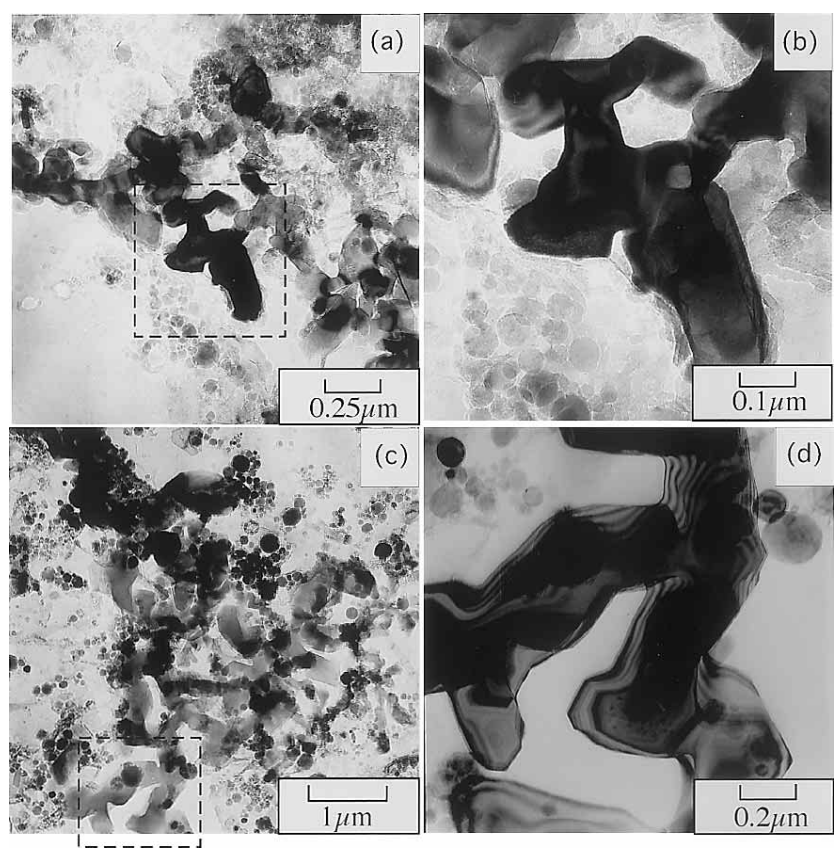

Fig. 3. (a), (b) Spherical and network-like inclusions in Sample 2-A maintained at $1873 \mathrm{~K}$ for $40 \mathrm{~min}$ (F.R.M.). (c), (d) Spherical and network-like inclusions in Sample 2-B maintained at $1873 \mathrm{~K}$ for $20 \mathrm{~min}$ (F.R.M.). (a), (b), (c), (d); black and grey parts show inclusions on the light grey carbon film.

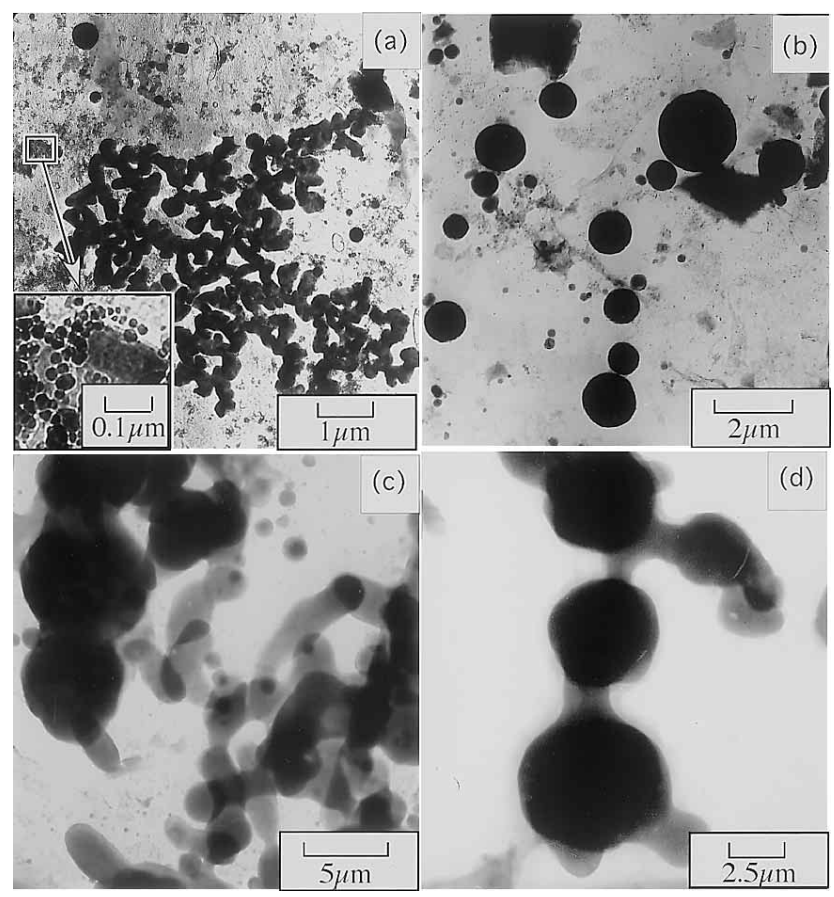

Fig. 4. (a) Spherical and network-like inclusion in Sample 1-A maintained at $1873 \mathrm{~K}$ for $5 \mathrm{~min}$ (F.R.M.). (b) Spherical inclusions in Sample 2-C maintained at $1873 \mathrm{~K}$ for 20 min (F.R.M.). (c) Network-like inclusion in Sample 2-C maintained at $1873 \mathrm{~K}$ for $20 \mathrm{~min}$ (F.R.M.). (d) Roundish coral-like inclusion in Sample 2-C maintained at $1873 \mathrm{~K}$ for $20 \mathrm{~min}$ (F.R.M.). (a), (b), (c), (d); black and grey parts show inclusions on the light grey carbon film.

were observed in the present experiments.

3.1.1. Dendritic Maple-like and Polygonal Inclusions

Dendritic and maple-like inclusions on filter were ob- served in Sample 1 by SEM (Figs. 2(a), 2(b), 2(c)) especially in the sample maintained 1 or $5 \mathrm{~min}$ at $1873 \mathrm{~K}$ and rarely in the sample maintained for longer times. Many of the dendritic and the maple-like inclusions would form during the first stage of deoxidation and, subsequently, float up growing and agglomerating. The agglomerated alumina would be tended to adhere to the crucible wall and, thus, it would not pass through the aperture of the crucible in Exp. 1 which was maintained at $1873 \mathrm{~K}$ for $15 \mathrm{~min}$ or more. However, on all the replica films for TEM observation of Sample 1-A, Sample 2-A and Sample 2-B including the replica films of Sample 1-A maintained at $1873 \mathrm{~K}$ for 1 or $5 \mathrm{~min}$, the dendritic and maple-like inclusions were not observed. It is probably due to the restricted area $(3 \times 3 \mathrm{~mm})$ of the cut filter for TEM observation. In contrast, by SEM, the wide area of the filter can be scanned and, thus, the dendritic and maple-like inclusions could be observed. In the Sample 2-C, which had been quenched in water with crucible, the inclusions seemed like agglomeration of some dendritic inclusions were observed (Fig. 2(d)).

Polygonal inclusions were observed in almost every sample of Exp. 1 and Exp. 2 by SEM and TEM.

The dendritic and maple-like inclusions are alumina, but they sometimes contain a small quantity of iron or silicon. The polygonal inclusion contains silicon and aluminum. The silicon contained could originate from silica impurities in the alumina crucible because there is no silicon source other than the silicon in electric iron which is lower than 7 mass ppm in the present experiment. The polygonal inclusions were observed even in Sample1-B which were cooled after holding at $1873 \mathrm{~K}$ for $1 \mathrm{~min}$. Thus, the silicon dissolution from crucible could occur from an early stage of iron melting or in the subsequent period where the temperature increased after melting.

The dendritic, maple-like and polygonal inclusions have similar length (a few $\mu \mathrm{m}$ to a few ten $\mu \mathrm{m}$ ) even in the samples quenched at different cooling speeds (Fig. 2). Thus, these inclusions are considered to be primary inclusions.

The identification of structure of the dendritic, maplelike and polygonal inclusions by electron diffraction analysis was not performed because of their thickness.

\subsubsection{Spherical Inclusions}

Spherical inclusions were observed in almost every sample of Exp. 1 and Exp. 2 by SEM and TEM (Fig. 2, Fig. 3 and Figs. 4(a), 4(b)). The spherical inclusions were alumina or hercynite. When the solidified iron was dissolved into iodine-methanol solution, wüstite spherical inclusions were also observed. The observed spherical wüstite inclusions would have precipitated at the iron with a high oxygen content. These wüstite inclusions should be secondary inclusion, because wüstite liquid particles could not be formed in liquid iron at $1873 \mathrm{~K}$ judging from the high solubility of oxygen in liquid iron.

In Figs. 3(a), 3(b), 3(c), 3(d) and Fig. 4(a), very small spherical inclusions are shown. Figures 3(a) and 3(b) show the inclusions in Sample 2-A (dissolved in iodine-methanol solution). Figures 3(c) and 3(d) show the inclusions in Sample 2-B (dissolved in iodine-methanol solution). Figures 3(b) and 3(d) are the magnified TEM images of encircled parts with broken line in Figs. 3(a) and 3(c), respec- 

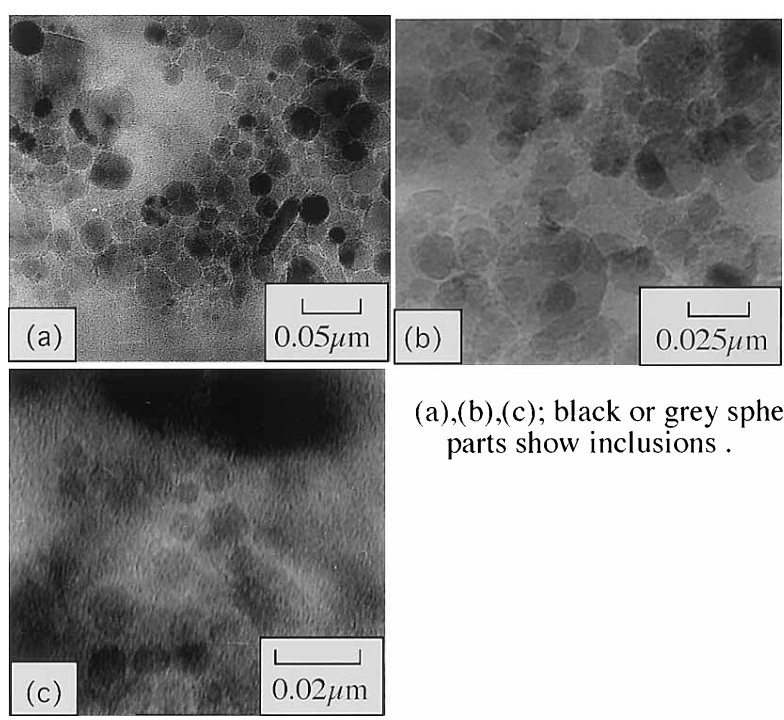

(a),(b),(c); black or grey spherical parts show inclusions .

Fig. 5. (a) Colony of fine spherical inclusions in Sample 1-A maintained at $1873 \mathrm{~K}$ for $5 \mathrm{~min}$. Several particles in the colony are shown as the hercynite by EDX. (b) Colony of fine spherical inclusions in Sample 2-A maintained at $1873 \mathrm{~K}$ for $40 \mathrm{~min}$. Several particles in the colony are shown as the alumina by EDX. (c) The finest inclusion observed in the present experiment in a colony of fine spherical inclusions in Sample 1-A maintained at $1873 \mathrm{~K}$ for 5 min. (a), (b), (c); black and grey spherical parts show inclusions.

tively. The diameter of spherical inclusions in Sample 1-A and Sample 2-A were around $30 \mathrm{~nm}$ and these in Sample 2$\mathrm{B}$ were around $60 \mathrm{~nm}$, although some variation in diameter was observed. Figures 4(a) and 4(b) show the spherical inclusions in Sample 2-A (dissolved in hydrochloric acid) and Sample 2-C (dissolved in hydrochloric acid), respectively. In Fig. 4(a), an enlarged photograph of encircled part with frame is shown, in which small spherical inclusions are observed. The spherical inclusions in the waterquenched sample have diameters in the range several hundreds nm to a few $\mu$ m (Fig. 4(b)) although a few inclusions with smaller diameter than $100 \mathrm{~nm}$ are present. In the result, the spherical inclusions are classified as secondary inclusions because their size changed with cooling rate (Figs. 3(a), 3(b), 3(c), 3(d) and Figs. 4(a), 4(b)). However, wide scattering of diameter is observed, especially in the sample quenched in water. The spherical inclusions formed at the first stage of cooling have chance to grow or coalesce until the iron was solidified. In contrast, those formed at the final stage of solidification have no time to grow. Thus, the variation of diameter would reflect the time interval between the first stage of cooling and the final stage of solidification.

The finest spherical alumina ever observed clearly in Sample 1-A and Sample 2-A was about $10 \mathrm{~nm}$ in diameter. These finest particles are often observed as a colony which would meet together in acid solution during filtration and the colony seems to consist of the particles of the same species because the pattern of EDX peaks taking for some particles were the same. In Fig. 5(a), a colony observed in Sample 1-A (maintained at $1873 \mathrm{~K}$ for $5 \mathrm{~min}$ ) whose several constituent particles show the peaks of hercynite is shown. In Fig. 5(b), a part of the colony of fine alumina particles of about $10-30 \mathrm{~nm}$ observed in Sample 2-A

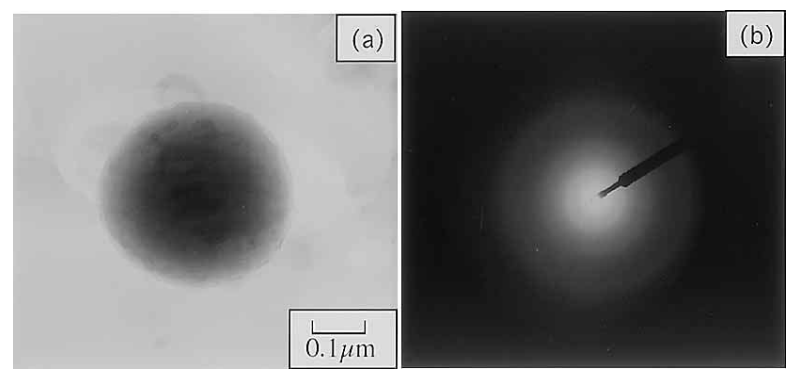

Fig. 6. (a) Spherical inclusion of amorphous silica in Sample 1A maintained at $1873 \mathrm{~K}$ for $60 \mathrm{~min}$. The grey, spherical part shows the inclusion on the light grey carbon film. (b) Electron diffraction pattern (halo pattern) of the amorphous silica in (a).

(maintained at $1873 \mathrm{~K}$ for $40 \mathrm{~min}$ ) is shown. Figure 5(c) shows the particles smaller than $10 \mathrm{~nm}$ observed in Sample 1-A (maintained at $1873 \mathrm{~K}$ for $5 \mathrm{~min}$ ). Figure $5(\mathrm{c})$ is the only one photograph in which such small particles could be seen in comparative clarity, but regretfully, these particles could not be identified by EDX, although they are hercynite or alumina. The photograph at large magnification of such colony is often unclear. This is probably due to the covering of carbon film and also to some overlapping and smallness of the particles.

A few large spherical inclusions with a diameter roughly from 1 to $5 \mu \mathrm{m}$ observed in Sample 1-A, Sample 1-B, Sample 2-A and Sample 2-B, which stand out from others are observed in every sample (Figs. 2(a), 2(b), 2(c)). The formation mechanism of these inclusions could be different from the secondary spherical inclusions and they would be primary inclusions because their size did not change with cooling rate.

In Sample 1-A maintained at $1873 \mathrm{~K}$ for $60 \mathrm{~min}$, a few spherical amorphous silica inclusions were observed (Figs. 6(a), 6(b)), which were almost pure silicas. The silica would originate from impurities in the alumina crucible. The amorphous silica could be secondary inclusion because primary silica was often observed as a polygonal inclusion containing alumina. Furthermore, it does not seem rational that the silica once dissolved in liquid iron could solidify, melt and solidify again as amorphous silica in the same liquid iron. However, the certain proof that amorphous silica is secondary inclusion is necessary.

\subsubsection{Network-like and Coral-like Inclusions}

In Fig. 3 and Fig. 4, network-like and coral-like inclusions are shown. The coral-like inclusion seems to be a fragment of a network-like inclusion and the network-like inclusion sometimes extends widely as a plane. The trunk of the network-like and the coral-like inclusion in Sample 1-A, Sample 2-A, Sample 1-B and Sample 2-B has an angular shape but that in Sample 2-C is roundish (Figs. 4(c), 4(d)). The coral-like and network-like inclusions are alumina, but they sometimes contain a small quantity of iron or silicon. The trunk thickness of the coral-like or the network-like inclusion in Sample 1-A and Sample 2-A was 100-200 nm (Figs. 3(a), 3(b)), that in Sample 1-B and Sample 2-B was 200-400 nm (Figs. 3(c), 3(d)), and that in Sample 2-C was $1-2 \mu \mathrm{m}$ (Figs. 4(c), 4(d)). Thus, the network-like and the coral-like inclusions in the samples 
cooled ultra-rapidly or quenched into a copper mold are secondary inclusions because their trunk thickness varies with cooling speed. However, the variation of the trunkthickness in the same sample was not so large as the spherical inclusions. Therefore, the stage of formation of the network-like and the coral-like inclusions might be restricted.

The network-like and the coral-like inclusions in Sample 2-C, which was water-quenched together with crucible were roundish (Figs. 4(c), 4(d)) in contrast to the angular shape of those observed in Sample 1-A, Sample 1-B, Sample 2-A and Sample 2-B (Figs. 3(a), 3(b), 3(c), 3(d)). The coral-like inclusions in Sample 2-C seemed to be the result of multiple union of spherical inclusions (Fig. 4(d)). The networklike inclusions in the Sample 2-C seems to be formed when several coral-like inclusions were superimposed upon one another (Fig. 4(c)). Thus, the formation mechanism of the network-like and coral-like inclusions in Sample 2-C might be different with those of the inclusion observed in the Sample 1-A, Sample 1-B, Sample 2-A and Sample 2-B. More investigation and consideration for the network-like and coral-like inclusions will be necessary.

\subsection{Structure of Spherical, Network-like and Coral- like Inclusions}

The network-like and coral-like inclusions are polycrystalline. The spherical inclusions were often observed as polycrystals. The diffraction pattern for spherical alumina inclusions revealed that most of them were the $\gamma$-alumina. However, another vague diffraction pattern with spots lined at narrow intervals often overlapped on it (Fig. 7(a)). The lattice constants for $\mathbf{a}$ and $\mathbf{b}$ axes of the $\gamma$-alumina (cubic; $\mathbf{a}=7.9, \mathbf{b}=7.9, \mathbf{c}=7.9$ ) and $\delta$-alumina (tetragonal; $\mathbf{a}=7.943$, $\mathbf{b}=7.943, \mathbf{c}=23.5$ ) are almost the same, and the lattice constant for the $\mathbf{c}$ axis of the $\delta$-alumina is about three times of that of the $\mathbf{a}$ and $\mathbf{b}$ axis. Thus, the two crystals could easily mix with one another and the vague overlapping pattern is
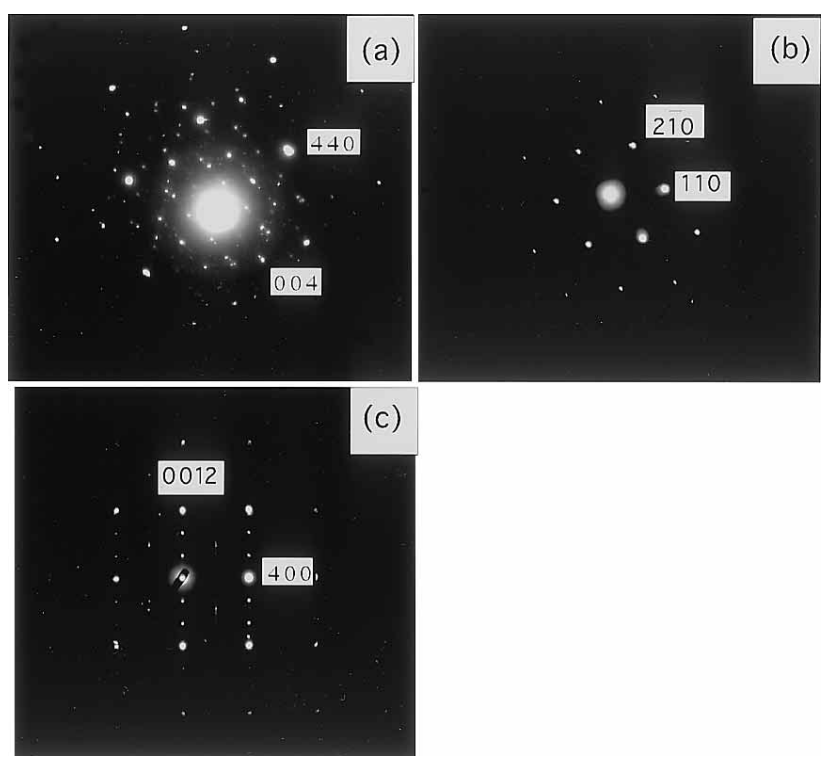

Fig. 7. Electron diffraction patterns of spherical and networklike inclusions. (a) Spherical $\gamma$-alumina in Sample 1-A maintained at $1873 \mathrm{~K}$ for $5 \mathrm{~min}$. (b) Network-like $\alpha$-alumina in Sample 2-B maintained at $1873 \mathrm{~K}$ for $20 \mathrm{~min}$. (c) Network-like $\delta$-alumina in Sample 2-A maintained at $1873 \mathrm{~K}$ for $40 \mathrm{~min}$. probably due to the small amount of mixing of $\delta$-alumina in $\delta$-alumina. Some of the network-like inclusions were identified as $\alpha, \gamma$ and $\delta$-alumina (Figs. 7(b), 7(c)). The diffraction pattern of network-like $\gamma$-alumina was similar to that of spherical $\gamma$-alumina, indicating the small amount of mixing of $\delta$-alumina. The electron diffraction pattern of the spherical silica observed in Sample 1-A (maintained at $1873 \mathrm{~K}$ for $60 \mathrm{~min}$ ) showed a halo pattern characteristic for amorphous material (Figs. 6(a), 6(b)).

The ratio of aluminum to iron in the hercynite was observed to vary and the wüstite inclusion often contained a small quantity of aluminum. Since wüstite and hercynite are soluble in one another in the liquid phase at $1873 \mathrm{~K}$ and have the same cubic crystalline structure, the hercynite nuclei can dissolve in liquid wüstite. The wüstite liquid particles containing hercynite would agglomerate through collision during cooling and crystallize as a solid solution, having no time to separate. Since the lattice constant of hercynite $(8.113 \AA)$ is nearly twice that of wüstite $(4.307 \AA)$, the wüstite containing a small amount of hercynite has often a similar diffraction pattern to hercynite, showing spots at the center of the two regular spots. On the contrast, the lattice constant of hercynite containing wüstite is larger than that of pure hercynite. In the present study, the inclusion formed from the solid solution which is insoluble to acid is called hercynite, because the solid solution containing significant amount of wüstite would dissolve into acid.

\subsection{Formation Mechanism of Unstable Aluminas and Amorphous Silica}

In the present experiment, the $\gamma$ and $\delta$-aluminas in addition to $\alpha$-alumina were observed not only in the iron having solidified immediately after aluminum deoxidation but also in iron having solidified $40 \mathrm{~min}$ after deoxidation. They are classified as the secondary inclusions.

Iwamoto $^{6)}$ and Adachi et al. ${ }^{9)}$ reported that the hydrogen absorbed into alumina could not be eliminated even through a heating to high temperature and suggested the possibility of hydrogen effect to the unstable alumina formation. However, the solubility of hydrogen in liquid iron is 20-30 mass ppm at $1873 \mathrm{~K}$ and $1 \mathrm{~atm} \mathrm{H}_{2}$. Thus, even if hydrogen might influence the formation of unstable alumina, the hydrogen will be consumed for the primary alumina formation and the effect to the secondary alumina formation will be scarce at this experiment.

The oxygen in liquid iron frequently exceeds the value for equilibrium with $\alpha$-alumina. The origin of the excess oxygen was already discussed in a previous report. ${ }^{14)}$ It was concluded that the excess oxygen originates in part from the suspension of fine alumina deoxidation products in liquid iron and in part from the supersaturation of oxygen or the supersaturation of an alumina-associated compound in liquid iron. ${ }^{14,15)}$ The supersaturated state could cause the secondary, unstable alumina formation from the consideration on the Ostwald's step rule. ${ }^{16,17)}$ Further, there is another important point to be considered, which is the presence of amorphous silica inclusion. Both the unstable aluminas and the amorphous silicas could be formed during cooling through similar mechanisms. However, the size dependence for amorphous silica inclusions with the cooling speed was not confirmed in this experiment because it was scarcely 
observed. The evidence for classifying amorphous silica as a secondary inclusion was obtained in an experiment on the $\mathrm{Cu}-\mathrm{O}-\mathrm{Si}$ system at $1423 \mathrm{~K}$ which will be discussed elsewhere. The present authors will make further detailed discussion in the next reports ${ }^{18)}$ on this mechanism of the unstable alumina formation in which the discussion on the mechanism of the network-like inclusion and amorphous silica inclusion formation will be included.

\subsection{Minimum Size of Inclusion}

The minimum diameter of alumina and hercynite inclusions observed in the present work is in the range from a few $\mathrm{nm}$ to $10 \mathrm{~nm}$. These inclusions were extracted by filtration of the hydrochloric acid solution in which iron sample was dissolved. However, Inoue et al. reported that fine alumina powder could be dissolved partly into mixed solution of nitric acid and hydrochloric acid. ${ }^{19)}$ Wakamatu reported that the alumina and the hercynite extracted from iron did not dissolve into nitric acid or mixed solution of nitric acid and hydrogen peroxide. ${ }^{20)}$ Thus, the species of acid or the process of alumina synthesis will probably have an influence on its solubility. Against this, Inoue et al. obtained the aluminum-deoxidized iron sample by heating at $1873 \mathrm{~K}$ in an alumina crucible and showed that the sum of the oxygen content calculated from the insoluble aluminum in acid (Insol Al) and the equilibrium oxygen value was smaller than the total oxygen. ${ }^{19)}$ From the result, they concluded that fine alumina in iron dissolved in acid. The present authors do not always deny the dissolution of very fine alumina, yet, have a question about the quantity of dissolution of alumina reported by Inoue et al. For instance, there should be silica inclusions even in the aluminum-deoxidized iron. In the sample heated for $1 \mathrm{~h}$ at $1873 \mathrm{~K}$, there should be the silica which originated from the impurity of alumina crucible. The silica dissolution should be depend firstly on the oxygen and silicon contents in liquid iron. However, under the same condition of liquid iron, it would depend on the purity of alumina crucible. ${ }^{21)}$ In the present experiment, even from a high purity, alumina crucible, the silica was dissolved in the liquid iron. Thus, the difference between the total oxygen and the sum of oxygen derived from Insol $\mathrm{Al}$ and equilibrium value is not always an indication of alumina dissolution. In addition, the equilibrium value of oxygen content is not yet determined correctly and Insol Al was detected even in the solidified iron which had been in the liquid state in equilibrium with $\alpha$-alumina. ${ }^{22)}$ However, it might be natural that the fine alumina (constructed of a few or a few ten molecules) would tend to dissolve into acid. If fine alumina can be dissolved in acid, the diameter about $10 \mathrm{~nm}$ of the finest alumina observed in the present experiment might have been larger in the liquid iron. On the other hand, very fine alumina inclusions, of smaller size than those observed in the present study, might exist in the iron sample and would not be observed since they would dissolve in the acid. As the authors described earlier from the calculations based on nucleation theory, the suspension of alumina particles should be present in liquid iron. ${ }^{14)}$ If the suspended alumina particle in liquid iron does not collide and coalesce during cooling and does not dissolve in acid, the smallest alumina with about $10 \mathrm{~nm}$ observed in the present study might be the suspended particle. On the other hand, the smallest alumina with about $10 \mathrm{~nm}$ diameter observed in the present study might be formed at the latest stage of solidification. In any case, further investigation of the finest inclusions present in an iron matrix is expected to clarify the nucleation mechanism.

\section{Conclusion}

Two types of experiment (Exp. 1 and Exp. 2) were performed. In both experiments, the iron-oxygen alloy was deoxidized with aluminum deoxidizer while heating at $1873 \mathrm{~K}$. The deoxidized iron was solidified using 3 different cooling methods: (1) the ultra-rapid cooling using twin rollers (ultra-rapid cooling), (2) the quenching of iron into copper mold, and (3) the quenching of the iron-bearing crucible in a water bath. The most rapid cooling rate achieved with (1), which was probably about $10^{5} \mathrm{~K} / \mathrm{s},{ }^{12)}$ followed (2) and (3).

In the sample in Exp. 1 and Exp. 2, dendritic, maple-like, polygonal, network-like, coral-like and spherical inclusions were observed. Almost all dendritic, maple-like, coral-like and network-like inclusions are alumina, but they sometimes contain a small quantity of iron or silicon. The polygonal inclusion contains silicon and aluminum. The spherical inclusion is alumina, hercynite or wüstite. The dendritic, maple-like and polygonal inclusions are classified as primary inclusions because they did not vary in size with differing the cooling rates. Many of the dendritic and the maple-like inclusions would form during the first stage of deoxidation. The network-like and coral-like inclusions in the sample cooled ultra-rapidly and quenched into copper mold and spherical inclusions are classified as secondary inclusions because they decreased in size with increases in cooling rate. However, a few large spherical inclusions, which would be primary inclusions, were present. The network-like and coral-like inclusions in the sample quenched into water might be formed in different mechanism.

The analysis of the electronic diffraction patterns of inclusions made clear that the $\alpha, \gamma$ and $\delta$-alumina were present as secondary inclusions. Amorphous silica inclusions were also observed. The supersaturated state of oxygen in liquid iron could cause the secondary, unstable alumina formation. The amorphous silica would be formed during cooling through similar mechanism.

The minimum diameter of spherical inclusions of alumina and hercynite observed in the present work is in the range from a few $\mathrm{nm}$ to $10 \mathrm{~nm}$.

\section{Acknowledgments}

A part of the present study was supported by the Ministry of Education, Science, Sports and Culture under Grant-in-Aid for Scientific Research (C), 1994-1995. The authors thank professor H. Era, Kyushu Institute of Technology, who offered valuable advice, and the Center for Instrumental Analysis at Kyushu Institute of Technology for the SEM, EPMA TEM and oxygen analysis.

\section{REFERENCES}

1) K. Oikawa, K. Ishida and T. Nishizawa: ISIJ Int., 37 (1997), 332.

2) H. Goto, K. Miyazawa and H. Honma: ISIJ Int., 36 (1996), 537.

3) H. Goto, K. Miyazawa and T. Kadoya: ISIJ Int., 35 (1995), 1477. 
4) K. Oikawa, H. Ohtani, K. Ishida and T. Nishizawa: ISIJ Int., 35 (1995), 402.

5) J. H. Shim, Y. W. Cho, S. H.Chung, J. D. Shim and D. N. Lee: Acta Mater, 47 (1999), 2751

6) N. Iwamoto: Tetsu-to-Hagané, 58 (1972), 787

7) F. Honda and K. Hirokawa: Tetsu-to-Hagané, 60 (1974), 287.

8) S. Watanabe, K. Takano, K. Moriya, Y. Tu and Y. Shiroishi: Tetsu-toHagané, 65 (1979), 383.

9) A. Adachi, N. Iwamoto and Y. Ueda: Tetsu-to-Hagané, 51 (1965), 1617.

10) M. Okubo, Y. Miyashita and R. Imai: Tetsu-to-Hagané, 54 (1968), S59.

11) JANAF Thermochemical Tables, Second Edn., ed. by D. R. Stull and H. Prophet, Horikoshi Laboratory, Tokyo, (1975), 1049.

12) H. S. Chen and C. E. Miller: Rev. Sci. Instrum., 41 (1970), 1237.

13) B. C. Lippens and J. H. de Bore: Acta Crystallogr., 17 (1964), 1312.
14) K. Wasai and K. Mukai: Metall. Mater. Trans. B, 30B (1999), 1065.

15) K. Wasai and K. Mukai: The Final Report of Ultra Clean Steel Research Group, Progress in Research on Ultra Clean SteelFundamental and Applied Aspects-, ISIJ, Tokyo, (1999), 3, No. 9511.

16) W. Ostwald: Z. Phy. Chem., 22 (1897), 289.

17) H. Singu and K. Ishihara: Bull. Jpn. Inst. Met., 25 (1986), 16.

18) K. Wasai and K. Mukai: ISIJ Int. 42 (2002), 467.

19) R. Inoue and H. Suito: The Final Report of Ultra Clean Steel Research Group, Progress in Research on Ultra Clean SteelFundamental and Applied Aspects-, ISIJ, Tokyo, (1999), 330, No. 9511.

20) S. Wakamatsu: Tetsu-to-Hagané, 57 (1971), 1360.

21) T. Dan, H. Yin, N. Aritomi, K. Ogawa and Y. Nakamura: J. Jpn. Inst.Met., 49 (1985), 865.

22) K. Wasai and K. Mukai: J Jpn. Inst. Met., 52 (1988), 1088. 